\title{
Update on the current modalities used to screen high risk youth for prediabetes and/or type 2 diabetes mellitus
}

\section{Preneet Cheema Brar, MD}

Division of Pediatric Endocrinology and Diabetes, New York University School of Medicine, New York, NY, USA
Received: 31 March, 2019

Revised: 3 June, 2019

Accepted: 11 June, 2019

Address for correspondence: Preneet Cheema Brar, MD

Division of Pediatric Endocrinology and Diabetes, New York University School of Medicine, 135 E 31 st Street, Second Floor, New York, NY 10016, USA

Tel: $+1-212-263-5940$

Fax: +82-212-263-9696

E-mail: preneet.brar@nyumc.org https://orcid.org/0000-0002-60658328
The modalities currently employed to screen for type 2 diabetes mellitus (T2DM)/ prediabetes are $\mathrm{HbA1}_{1}$, fasting plasma glucose (FPG), and 2-hour plasma glucose (PG) during an oral glucose tolerance test (OGTT). The purpose of this review is to highlight the positive qualities and pitfalls of these diagnostic modalities and reflect on the most reasonable and effective approach to screen high risk youth. Given its inherent preanalytical advantages, glycated hemoglobin ( $\left.\mathrm{HbA} 1_{c}\right)$ continues to be the preferred diagnostic modality used by pediatricians to screen high risk youth. However, when the three aforementioned tests are performed in youths of different races/ethnicities, discrepant results for T2DM/prediabetes are observed. The prevalence rates for T2DM vary from $0.53 \%$ in Chinese youth (including youth of all body mass indexes) to $18.3 \%$ in high-risk, overweight, obese Korean youth. Moreover, the FPG is abnormal (>100 less than $<126 \mathrm{mg} / \mathrm{dL}$ ) in $15 \%$ of Korean youth versus $8.7 \%$ of Chinese youth. The prevalence rates for prediabetes are $1.49 \%$ in Chinese youth versus $21 \%$ in Emirati youth ( $\mathrm{HbA} 1 \mathrm{c}, 5.7 \%-6.4 \%)$. The coefficient of agreement, $k$, between these screening tests for T2DM are fair, 0.45-0.5 across all youth. However, using $\mathrm{HbA} 1 \mathrm{c}$ as a comparator, the agreement is weak with FPG ( $k=0.18$ in German youth versus $\mathrm{k}=0.396$ in Korean youth). The American Diabetes Association (ADA) Standards of Medical Care Guidelines define "high risk youth" who need to be tested for T2DM and/or prediabetes. OGTT and HbA1c do not always detect T2DM in similar individuals. $\mathrm{HbA} 1_{\mathrm{c}}$ may not be an ideal test for screening Hispanic and African American youth. FPG and OGTT are suitable screening tests for youth of ethnic minorities and those with cystic fibrosis or hemoglobinopathies. Performing all three tests either together or sequentially may be the only way to encompass all youth who have aberrations in different aspects of glucose homeostasis.

Keywords: Type 2 diabetes mellitus, Prediabetic state, Glycated hemoglobin A, Fasting plasma glucose, Oral glucose tolerance test, Youth, Screening tests

\section{Introduction}

Prediabetes, a condition in which the glucose levels are not high enough to meet the criteria of diabetes but also cannot be considered normal, is an intermediate state along the spectrum of glucose homeostasis.

Table 1 defines type 2 and prediabetes as per the Standard of Medical Care in Diabetes update in $2019 .{ }^{1)}$ In 2010 , the ADA added glycated hemoglobin ( $\mathrm{HbA} 1_{\mathrm{c}}$ ) of $\geq 6.5 \%$ as diagnostic criteria for type 2 diabetes mellitus (T2DM) and made $\mathrm{HbAl}$ c of 5.7\%-6.4\% (39-47 $\mathrm{mmol} / \mathrm{mol}$ ) as the criteria for prediabetes. ${ }^{1 .}$ The risk for developing diabetes is a continuum and spans from low below the cutoff values to disproportionately higher at the upper end of 
this range.

\section{Prevalence of type 2/prediabetes in youth}

The obesity epidemic has led to an exponential increase in prediabetes and/or mellitus (T2DM, and this rise has been the most dramatic in Hispanic, American-Indian and AfricanAmericans populations. ${ }^{2,3)}$ Thirty years ago, T2DM in youth was considered rare; the first cases of T2DM were reported in the mid-1990s. ${ }^{4}$ However, the last decade has seen a dramatic increase in the numbers of youth with T2DM, especially in racial and ethnic minorities, ${ }^{2)}$ and projections suggest that there will be 1,000,000 youths with T2DM in the United States by the year 2050.

The prevalence rates for prediabetes in youth are highly variable and range from $18 \%-28 \%$ in obese youth. ${ }^{6}$ The conversion rate of prediabetes to $\mathrm{T} 2 \mathrm{DM}$ is accelerated in youth, with studies showing a 15\% annual reduction in betacell function with a mean transition time from prediabetes to diabetes of 2.5 years more so than in adults. ${ }^{7)}$ Therefore, in high risk youth with prediabetes, screening, diagnosis, and therapeutic lifestyle counselling are paramount for diabetes prevention.

Table 2 defines the risk-based screening criteria in order to provide guidance to pediatricians for initial and followup diabetes screening in high risk youth. ${ }^{8)}$ The value of the diagnostic tools approved by the ADA have been adopted to

Table 1. Categories of increased risk for diabetes (prediabetes) ${ }^{*}$ FPG $100 \mathrm{mg} / \mathrm{dL}(5.6 \mathrm{mmol} / \mathrm{L})$ to $125 \mathrm{mg} / \mathrm{dL}(6.9 \mathrm{mmol} / \mathrm{L})(\mathrm{IFG})$

$\mathrm{OR}$

2-hr PG during 75-g OGTT $140 \mathrm{mg} / \mathrm{dL}$ (7.8 mmol/L) to $199 \mathrm{mg} / \mathrm{dL}$ $(11.0 \mathrm{mmol} / \mathrm{L})(\mathrm{IGT})$

$\mathrm{OR}$

A1c 5.7\%-6.4\% (39-47 mmol/mol)

FPG, fasting plasma glucose; $P$ G, plasma glucose; IFG, impaired fasting glucose; OGTT, oral glucose tolerance test; IGT, impaired glucose tolerance.

"For all 3 tests, risk is continuous, extending below the lower limit of the range and becoming disproportionately greater at the higher end of the range.

Adapted from American Diabetes Association. Diabetes Care 2019;42(Suppl 1):S13-28.' help identify asymptomatic youth at an increased risk for T2DM and/or prediabetes.

\section{FPG and 2-hour PG as diagnostic tools}

Historically, the diagnostic thresholds for impaired fasting glucose (IFG) and 2-hour plasma glucose (PG) were established from epidemiologic studies in adults, which found that the diabetes-related complication of retinopathy was prevalent and increased exponentially above the fasting PG cut off of $126 \mathrm{mg} /$ $\mathrm{dL}$ and the 2-hour PG cutoff of $200 \mathrm{mg} / \mathrm{dL}$, thus defining these thresholds. ${ }^{9}$ The World Health Organization defines IFG as 110 $\mathrm{mg} / \mathrm{dL}(6.1 \mathrm{mmol} / \mathrm{L})$.

The oral glucose tolerance test (OGTT) diagnostic criteria have been considered the "gold standard" since their inception in 1997. Fasting plasma glucose (FPG) and 2-hour PG cut off values have not been validated in youth, and studies to do so are unlikely.

\section{Benefits and pitfalls of FPG and 2-hour OGTT}

The OGTT provides an overview of different aspects of beta cell function (fasting and prandial) within the background of insulin resistance, which is present in most obese youth. Moreover, it can illustrate whether there is more hepatic insulin resistance (higher FPG) versus postprandial resistance (higher 2-hour PG).

The main disadvantages of the OGTT are as follows: (1) the requirement for an overnight fast of at least 8 hours, which could be a challenge for young children; (2) difficulty in staffing pediatric offices to conduct the OGTT during office hours; (3) the length of the test (2 hours) can be a deterrent for both families and physicians; and (4) Some pediatricians do not feel comfortable ordering or interpreting OGTT results. The major caveat of OGTT in pediatrics is that it has poor reproducibility, and there have been no validation studies in youth. ${ }^{10)}$ A study at Yale in youths with prediabetes who were followed with serial OGTTs revealed that $50 \%$ of youths with prediabetes reverted to normal glucose tolerance, whereas $24 \%$ progressed from prediabetes to diabetes. ${ }^{11)}$

Below an $\mathrm{HbA1}$ c level of 7\%, 2-hour PG reflects prandial hyperglycemia increases before increases of FPG, whereas in patients with an $\mathrm{HbAl}$ c level above $8 \%$, the contribution of basal

Table 2. Risk-based screening for type 2 diabetes or prediabetes in asymptomatic children and adolescents in a clinical setting ${ }^{*}$

Plus one or more additional risk factors based on the strength of their association with diabetes as indicated by evidence grades:

- Maternal history of diabetes or gestational diabetes mellitus during the child's gestation

- Family history of type 2 diabetes in first- or second-degree relative

- Race/ethnicity (Native American, African American, Latino, Asian American, Pacific Islander)

- Signs of insulin resistance or conditions associated with insulin resistance (acanthosis nigricans, hypertension, dyslipidemia, polycystic ovary syndrome, or small-for-gestational-age birth weight)

Criteria: overweight (body mass index $>85$ th percentile for age and sex, weight for height $>85$ th percentile, or weight $>120 \%$ of ideal for height)

*Age less than 18 years.

Adapted from Arslanian S, et al. Diabetes Care 2018;41:2648-68. ${ }^{8)}$ 
hyperglycemia to overall hyperglycemia becomes predominant. So, youth with impaired glucose tolerance may have nearnormal $\mathrm{HbAl}_{\mathrm{c}}$, and these youth will be missed if only FPG is done without an OGTT.

Although FPG requires fasting, its advantage is that it requires only one blood draw. FPG is affected by stress/illness and drops by $5 \%-7 \%$ per hour in a sample due to glycolysis. Both FPG and OGTT have intra-individual variability, which is much higher for OGTT at $12.7 \%$ versus $5.7 \%-8.3 \%$ for FPG. ${ }^{12)}$

\section{$\mathrm{HbA} 1_{\mathrm{c}}$ as a diagnostic tool}

The $\mathrm{HbA} 1_{c}$ test was used in prospective studies in adults, and it was found to have a consistent linear association with the development of diabetes. Systematic reviews of over 40,000 adults from 16 studies have shown that the 5 -year risk for developing diabetes was $9 \%-25 \%$ when $\mathrm{HbAl}_{\mathrm{c}}$ was $\geq 5.7 \%$, and this risk increased to $25 \%-50 \%$ for $\mathrm{HbAl} 1_{\mathrm{c}} \geq 6 \%-6.5 \% .{ }^{13)}$ This data formed the ADA's basis in using $\mathrm{HbAl}_{\mathrm{c}}$ as screening criteria for T2DM/prediabetes in 2010. Since the acceptance of HbAl c as a screening tool, there has been a tremendous appeal among pediatricians to evaluate $\mathrm{HbA1} 1_{c s}$.

\section{Benefits and pitfalls of $\mathrm{HbA} 1 \mathrm{c}$}

$\mathrm{HbA} 1_{\mathrm{c}}$ is not a direct measure of glycemia. It is an indirect measure, and it represents the amount of hemoglobin with glucose attached to the $\mathrm{N}$-terminal valine of the beta chain, thus reflecting blood glucose levels over the previous 2-3 months (based on red blood cell turnover). $\mathrm{HbA} 1_{\mathrm{c}}$ must be performed using a method that is certified by the National Glycohemoglobin Standardization Program (www.ngsp.org). The major advantages for $\mathrm{HbAl}_{\mathrm{c}}$ are that it does not require fasting, it has less pre-analytical and glycemic variability, and it is not affected by stress or illness. However, $\mathrm{HbAl}$ c has lower sensitivity and a higher cost, and it is availability is limited in many developing countries.

\section{Nonglycemic factors that affect $\mathrm{HbA} 1_{c}$ levels in youth}

(1) Red blood cell (RBC) turnover: Lower $H b A 1_{c}$ values are observed in conditions of high RBC turnover, such as cystic fibrosis, ${ }^{14)}$ hemorrhage, and hemolysis, and higher $\mathrm{HbAl}$ c values are seen when RBC turnover is slowed down, as in spherocytosis and iron deficiency anemia. ${ }^{15)}$

(2) Medications: Retroviral drugs, ${ }^{16)}$ dapsone, hydroxyurea, and vitamins $\mathrm{C} \& \mathrm{E}$ can falsely lower $\mathrm{HbA1}$, and aspirin can interfere with the laboratory assay and artificially raise the HbAlc value. ${ }^{16)}$

\section{Hemoglobinopathies}

Hemoglobin variants, such S, C, D, and E, are substitutions for the B chain and can interfere with certain assays. More information about hemoglobinopathies is available at ngsp.org. African American youth who are heterozygous for the $\mathrm{S}$ trait could have an average $\mathrm{HbAl}_{\mathrm{c}}$ which is $0.3 \%$ higher for any given glucose level. ${ }^{177}$ When corrected for age, body mass index (BMI), sex, and blood pressure, the $\mathrm{HbA} 1_{c}$ levels in African Americans is higher compared to Caucasians, which could be the result of inherent differences in glycation triggers besides the racial differences in the presence of traits. ${ }^{17)}$

\section{Age}

There is an age-related linear increase in $\mathrm{HbAl}_{\mathrm{c}}$ values for the same levels of glycemia, suggesting more efficient glycation in youth compared to adults. ${ }^{18}$

\section{Is $\mathrm{HbA} 1_{\mathrm{c}}$ the ideal test?}

After $\mathrm{HbAl}_{\mathrm{c}}$ came to the forefront as a screening test in 2010, several pediatric studies reported the validity of the $\mathrm{HbAl}_{\mathrm{c}}$.

Nowicka et al. ${ }^{19)}$ compared $\mathrm{HbA} 1_{\mathrm{c}}$ to the gold standard OGTT in over 1,000 patients. Of the 347 obese youth with prediabetes on the OGTT, 240 subjects had an $\mathrm{HbA} 1_{c}$ below the cutoff value of $5.7 \%$. This study highlighted the unacceptably low sensitivity of $\mathrm{HbA} 1_{\mathrm{c}}$ as a screening test. Brar et al. ${ }^{6}$ studied 149 obese youth who were referred for $\mathrm{HbA} 1_{\mathrm{c}}$ values $\geq 5.7 \%$ who then underwent an OGTT. At a sensitivity of $75 \%$ and a specificity of $57 \%, \mathrm{HbAl}_{\mathrm{c}}$ has been unreliable due to its high false positive rate.

Buse et al. ${ }^{20)}$ studied 3,980 sixth-grade youth and found that $\mathrm{HbAl}$ c and IFG as screening tools defined different ethnic/ racial groups. Elevated $\mathrm{HbAl} 1_{c}$ was associated with the Hispanic and Black races, strong family history of diabetes, higher BMIs, higher waist circumferences and higher insulin values. High risk $\mathrm{HbA} 1_{\mathrm{c}}$ was seen in 128 subjects (3.2\%), and abnormal FPG was observed in 635 subjects (16\%). IFG was found in youth who were mostly Hispanic, it being fivefold more common when compared to $\mathrm{HbAl}_{\mathrm{c}}$ in these children. The authors, among others, proposed that these contradictions call into question the utility of $\mathrm{HbAl}_{\mathrm{c}}$ as a standalone screening test. The conversion rate to diabetes was $0.8 \%$ for $H b A 1_{c}$ and $1.1 \%$ for FPG in a 2-year follow-up evaluation.

Several studies indicate that using adult cutoff points for $\mathrm{HbA} 1_{c}$ to predict $\mathrm{T} 2 \mathrm{DM} /$ prediabetes significantly underestimates the prevalence of these conditions in the pediatric and adolescent population, and consequently, a lower $\mathrm{HbA1} 1_{\mathrm{c}}$ cutoff point has to be proposed for children. ${ }^{19,21)}$

\section{How do these tests do when compared to each other?}

A retrospective review of 72 papers analyzed the comparisons of these three tests in youth. Table 3 highlights the findings of 5 papers.

Using FPG and $\mathrm{HbAl}_{\mathrm{c}}$, Yang et al. ${ }^{22)}$ studied the prevalence 
of T2DM and/or prediabetes in 7,519 Chinese youth in grades 1,7 and 10 in Shenzhen province. The cross-sectional study found a T2DM prevalence rate of $0.53 \%(n=4)$. Additionally, the prevalence of an abnormal FPG prevalence was 7 fold higher than the prevalence of an abnormal $\mathrm{HbAl}_{\mathrm{c}}(8.72 \%$ vs. $1.49 \%$ ), and the odds ratio for an abnormal result for either test was higher for boys than girls (odds ratio, 1.21). As the authors did the testing on all youth irrespective of BMI, they found an interesting U-shaped curve, indicating higher rates of T2DM/ prediabetes for underweight and obese youth. The proportion of prediabetes was higher for males than females, and the proportion decreased with grade for males but increased for females.

Al Amiri et al. ${ }^{23)}$ studied youth from 16 schools across the United Arab Emirates, a country with one of the highest prevalences of diabetes in the world. Of the 1,434 youth who were screened, 433 were overweight or obese. Among these 1,034 youth, $0.87 \%$ had T2DM. A significantly higher proportion of children had prediabetes using the results from the $\mathrm{HbAl}$ c criteria rather than the OGTT criteria $(21.9 \%$ vs. $5.4 \%)$. $H b A l_{c}$ results were discrepant for prediabetes but not for T2DM.

Nam et al. ${ }^{24)}$ simultaneously performed OGTT and $\mathrm{HbAl}_{\mathrm{c}}$ in 384 high risk overweight and obese youth across 6 hospitals in South Korea. The overall prevalence of T2DM and prediabetes was $18 \%$ and $31.1 \%$, respectively. The authors proposed that $\mathrm{HbA} 1_{\mathrm{c}}$ of $6.2 \%$ had a sensitivity of $91.5 \%$ and specificity of $93.7 \%$ with an area under the curve (AUC) of 0.972 . For prediabetes 5.8 had a statistical significance with an $\mathrm{AUC}=0.795$ ( $95 \%$ confidence interval $[\mathrm{CI}], 0.750-0.840$ ), with a sensitivity of $64.1 \%$ and a specificity of $83.8 \%$ to screen for prediabetes. The authors found that 49 of the youths with T2DM fulfilled all three diagnostic criteria, and five youth fulfilled the OGTT criteria for $\mathrm{T} 2 \mathrm{DM}$ but no the ADA's $\mathrm{HbA} \mathrm{l}_{\mathrm{c}}$ criteria of $6.5 \%$. The authors demonstrated that the kappa coefficient of agreement between the two tests could be interpreted as fair (0.21-0.40) to moderate (0.41-0.60). For prediabetes, $9.4 \%$ of the youth fulfilled all the criteria, and $16.1 \%$ of the subjects would have missed without an OGTT as they only had an abnormal 2-hour PG. Because the pediatric cut-off value for $\mathrm{HbAl}$ c across racial/ ethnic groups remains obscure, the authors recommended the combination of fasting and 2-hour glucose levels, in addition to $\mathrm{HbAl}_{c}$, as the best modality to screen for T2DM and/or prediabetes at this time.

Khokhar et al. ${ }^{25)}$ studied predominantly African American and Caribbean youth $(\mathrm{n}=230)$ and found that $\mathrm{HbAl}$ c had a receiver operating curve of 0.64 (95\% CI, 0.56-0.72), showing that $\mathrm{HbA} 1_{\mathrm{c}}$ had poor sensitivity for detecting prediabetes when compared to OGTT. While $56 \%$ of the cohort had an elevated $\mathrm{HbAl}$, 26\% had an abnormal OGTT result, with 18\% testing positive for both $\mathrm{HbAl}_{\mathrm{c}}$ and OGTT. All tests were done within a 3-month period. The authors proposed that $\mathrm{HbA} 1_{\mathrm{c}}$ when combined with BMI $z$-score and homeostatic model of insulin resistance in a regression model was a better predictor of prediabetes in youth.
Ehehalt et al. ${ }^{26)}$ studied a large cohort of German youth $(\mathrm{n}=4,848)$ from several hospitals across Germany. The prevalence of T2DM was $0.02 \%(n=115)$, and these youth met one of the ADA criteria for T2DM. For those with T2DM, the OGTT had a sensitivity of $44.0 \%(95 \%$ CI, 30.0-58.7) and a specificity of $99.6 \%$ (95\% CI, 99.3-99.7), whereas $\mathrm{HbAl}_{\mathrm{c}}$ had a sensitivity of $84.0 \%(95 \% \mathrm{CI}, 70.9-92.8)$ and a specificity of 99.3\% (95\% CI, 99.0-99.5). The results were discordant for those whose 2-hour glucose levels were $\geq 200 \mathrm{mg} / \mathrm{dL}$ diabetes, median FPG, and median $\mathrm{HbA} 1_{c}$ levels were $110 \mathrm{mg} / \mathrm{dL}$ and $6.3 \%$ (prediabetes) range. There was a high correlation $(r=0.73)$ between FPG and 2-hour PG in those with confirmed T2DM $(\mathrm{n}=50)$ on repeat testing with either an OGTT and/or HbAlc. Prediabetes was highest with $\mathrm{HbAl}$ c criteria at $23 \%$ vs. FPG $12 \%$ vs. 2 -hour PG $8 \%$. In those youth with an abnormal $\mathrm{HbA1}$, the correlation between $\mathrm{HbA} 1_{\mathrm{c}}$ and FPG was weak at $r=0.18$. However, the authors compared FPG+2-hour-PG (OGTT) vs. glycated hemoglobin and found an improvement in correlation with $\mathrm{HbAl}_{\mathrm{c}}$ (\%) (log-transformed data, $r=0.21, \mathrm{n}=4,848$, $P<0.001)$. The authors surmise that these weak correlations were much lower than those reported in adults, possibly due to the fact that the tests measure different disorders of glucose metabolism. Moreover, the reproducibility of OGTT continues to be an area of controversy. ${ }^{26)}$

\section{What are the inadequacies of the current diagnostic criteria for T2DM and/or prediabetes?}

(1) The screening tests results are discrepant according to the ethnicity/race of the youth, so the "one size fits all" examination cannot be used for youth from different parts of the world.

(2) $\mathrm{HbAl}_{\mathrm{c}}$ as a standalone screening test for T2DM and/or prediabetes can result in the overdiagnosis of prediabetes, and many youths will have to undergo unnecessary OGTTs. The relevant literature contradicts the call for lowering $\mathrm{HbAl} 1_{c}$ cutoff values for youth, as suggested by several studies. Youths with a high $\mathrm{HbAl}_{\mathrm{c}}$ above $6.2 \%$ must have an OGTT to establish the diagnosis of T2DM. ${ }^{27}$

(3) Patients with a significant elevation of $\mathrm{HbAl}_{\mathrm{c}} \geq 5.8 \%-6 \%$ or higher and normal OGTT results are at a higher risk for developing diabetes. The poor reproducibility of the OGTT in these situations may warrant testing $\mathrm{HbA} 1_{\mathrm{c}}$ levels at threemonth intervals, especially if the patient's BMI is increasing.

(4) Although OGTT is not an "ideal test," it is the only test clinicians can use to assess prandial hyperglycemia. Youths with near-normal $\mathrm{HbAl}_{\mathrm{c}}$ values who have IGT will be missed if only FPG is tested.

\section{Are there any alternatives to the current screening tests?}

(1) Short-term markers of glycemia, such as 1,5-anhydroglucitol, glycated albumin and fructosamine, reflect glycemia 


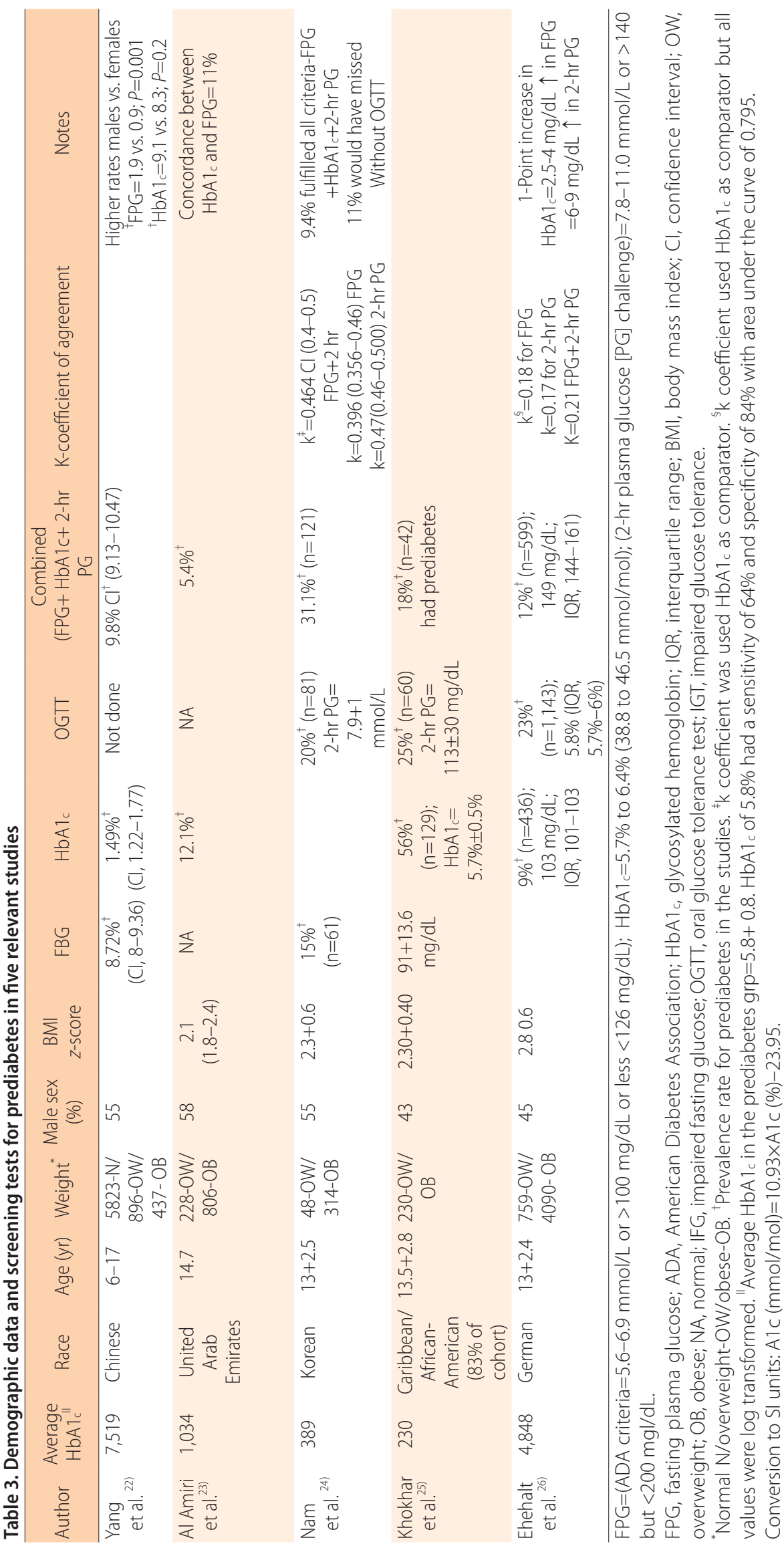


ranging from 48 hours to 4 weeks, and they are promising for diabetes more so than for prediabetes screening. ${ }^{28)}$ Chan et al. ${ }^{29)}$ studied these markers in 14.3-year-old high risk youth $(\mathrm{n}=56)$ who were on a continuous glucose monitor. These markers predicted the glycemic variability as reported by the continuous glucose monitoring data independent of $\mathrm{HbAl} \mathrm{l}_{\mathrm{c}}$.

(2) A 1-hour PG value of $155 \mathrm{mg} / \mathrm{dL}(8.6 \mathrm{mmol} / \mathrm{L})$ has been assessed for identifying prediabetes in adults. ${ }^{30)}$ Jagannathan et $\mathrm{al}^{311}$ studied 212 adults and found the $\mathrm{k}$ coefficient of agreement for one-hour PG was 2 fold higher than $\mathrm{HbAl}_{\mathrm{c}}$ for prediabetes. Abdul-Ghani found that the receiver operating characteristic (ROC) curve for 1-hour PG was much higher than the $\mathrm{HbAl}$. ROC curve for prediabetes ( $r=0.84$ vs. 0.73 ). ${ }^{32)}$ Kasturi et al ${ }^{33)}$ studied the reproducibility and predictive value of 1-hour PG compared to the standard OGTT. Nondiabetic adolescent girls with obesity underwent a multiple-sample OGTT at baseline $(\mathrm{n}=93), 6$ weeks $(\mathrm{n}=83)$, and 1 year $(\mathrm{n}=72)$. The shorter 1 -hour OGTT provided the diagnostic equivalent of the standard OGTT with the advantage of being a shorter risk assessment.

\section{Conclusions}

$\mathrm{HbAl}$, FPG, and 2-hour PG provide a dynamic overview of different aspects of glucose homeostasis, although the results from these tests are often discrepant based on the race/ethnicity of the youth in which they are performed. Of note, when done together they can perform below their diagnostic threshold for prediabetes in $25 \%$ of youth for up to 2 years preceding the diagnosis of diabetes.

Risk-based screening for T2DM and/or prediabetes should be considered in youth at the onset of puberty or $\geq 10$ years of age in overweight and obese youth who have 2 additional risk factors (Table 2). In high risk ethnic groups, such as African Americans and Hispanic youth, a FPG and/or OGTT may be more suitable than $\mathrm{HbA} 1_{c}$. Based on our current literature review to date, there is limited data to support using $\mathrm{HbAl}_{\mathrm{c}}$ as a standalone screening test for high risk youth. As the pediatric cut-off values for $\mathrm{HbA} 1_{\mathrm{c}}$ across racial/ethnic groups remain unclear, it is appropriate to recommend the combination of fasting and 2-hour glucose levels, in addition to $\mathrm{HbAl}_{c}$, as the best way to screen for T2DM and/or prediabetes at this time.

\section{Conflicts of interest}

No potential conflict of interest relevant to this article was reported.

\section{References}

1. American Diabetes Association. 2. Classification and Diagnosis of Diabetes: Standards of Medical Care in Diabetes-2019. Diabetes Care 2019;42(Suppl 1):S13-28.

2. Dabelea D, Mayer-Davis EJ, Saydah S, Imperatore G, Linder B, Divers J, et al. Prevalence of type 1 and type 2 diabetes among children and adolescents from 2001 to 2009. JAMA 2014;311:1778-86.

3. Dabelea D, Pettitt DJ, Jones KL, Arslanian SA. Type 2 diabetes mellitus in minority children and adolescents. An emerging problem. Endocrinol Metab Clin North Am 1999;28:709-29.

4. Libman I, Arslanian SA. Type II diabetes mellitus: no longer just adults. Pediatr Ann 1999;28:589-93.

5. Imperatore G, Boyle JP, Thompson TJ, Case D, Dabelea D, Hamman RF, et al. Projections of type 1 and type 2 diabetes burden in the U.S. population aged $<20$ years through 2050: dynamic modeling of incidence, mortality, and population growth. Diabetes Care 2012;35:2515-20.

6. Brar PC, Mengwall L, Franklin BH, Fierman AH. Screening obese children and adolescents for prediabetes and/or type 2 diabetes in pediatric practices: a validation study. Clin Pediatr (Phila) 2014;53:771-6.

7. Weiss R. Impaired glucose tolerance and risk factors for progression to type 2 diabetes in youth. Pediatr Diabetes 2007;8 Suppl 9:70-5.

8. Arslanian S, Bacha F, Grey M, Marcus MD, White NH, Zeitler P. Evaluation and management of youth-onset type 2 diabetes: a position statement by the American Diabetes Association. Diabetes Care 2018;41:2648-68.

9. Report of the Expert Committee on the Diagnosis and Classification of Diabetes Mellitus. Diabetes Care 1997;20:1183-97.

10. Kleber M, Lass N, Papcke S, Wabitsch M, Reinehr T. One-year follow-up of untreated obese white children and adolescents with impaired glucose tolerance: high conversion rate to normal glucose tolerance. Diabet Med 2010;27:516-21.

11. Weiss R, Taksali SE, Tamborlane WV, Burgert TS, Savoye M, Caprio S. Predictors of changes in glucose tolerance status in obese youth. Diabetes Care 2005;28:902-9.

12. Gallardo TV, Avila AA, Unuane MN, Codner E. Fasting glucose versus oral glucose tolerance test for detection of glucose intolerance in obese children. Rev Med Chil 2006;134:1146-52.

13. International Expert Committee. International Expert Committee report on the role of the $\mathrm{A} 1 \mathrm{C}$ assay in the diagnosis of diabetes. Diabetes Care 2009;32:1327-34.

14. Moran A, Brunzell C, Cohen RC, Katz M, Marshall BC, Onady G, et al. Clinical care guidelines for cystic fibrosisrelated diabetes: a position statement of the American Diabetes Association and a clinical practice guideline of the Cystic Fibrosis Foundation, endorsed by the Pediatric Endocrine Society. Diabetes Care 2010;33:2697-708.

15. Brooks AP, Metcalfe J, Day JL, Edwards MS. Iron deficiency and glycosylated haemoglobin A. Lancet 1980;2:141.

16. Unnikrishnan R, Anjana RM, Mohan V. Drugs affecting $\mathrm{HbA1}$ c levels. Indian J Endocrinol Metab 2012;16:528-31.

17. Lacy ME, Wellenius GA, Sumner AE, Correa A, Carnethon MR, Liem RI, et al. Association of sickle cell trait with hemoglobin Alc in African Americans. JAMA 2017;317:507-15. 
18. Pani LN, Korenda L, Meigs JB, Driver C, Chamany S, Fox CS, et al. Effect of aging on A1C levels in individuals without diabetes: evidence from the Framingham Offspring Study and the National Health and Nutrition Examination Survey 2001-2004. Diabetes Care 2008;31:1991-6.

19. Nowicka P, Santoro N, Liu H, Lartaud D, Shaw MM, Goldberg R, et al. Utility of hemoglobin A(1c) for diagnosing prediabetes and diabetes in obese children and adolescents. Diabetes Care 2011;34:1306-11.

20. Buse JB, Kaufman FR, Linder B, Hirst K, El Ghormli L, Willi $S$, et al. Diabetes screening with hemoglobin $A(1 \mathrm{c})$ versus fasting plasma glucose in a multiethnic middle-school cohort. Diabetes Care. 2013;36:429-35.

21. Lee JM, Wu EL, Tarini B, Herman WH, Yoon E. Diagnosis of diabetes using hemoglobin Alc: should recommendations in adults be extrapolated to adolescents? J Pediatr 2011;158:947-52.e1-3.

22. Yang C, Ding Z, Zhou H, Chen D, Huang Z, Yang C, et al. Prevalence of prediabetes by the fasting plasma glucose and $\mathrm{HbA} 1_{c}$ screening criteria among the children and adolescents of Shenzhen, China. J Diabetes 2018 Jul 4 [Epub]. https://doi.org/10.1111/1753-0407.12820.

23. Al Amiri E, Abdullatif M, Abdulle A, Al Bitar N, Afandi EZ, Parish $\mathrm{M}$, et al. The prevalence, risk factors, and screening measure for prediabetes and diabetes among Emirati overweight/obese children and adolescents. BMC Public Health 2015;15:1298.

24. Nam HK, Cho WK, Kim JH, Rhie YJ, Chung S, Lee KH, et al. $\mathrm{HbA} 1_{\mathrm{c}}$ cutoff for prediabetes and diabetes based on oral glucose tolerance test in obese children and adolescents. J Korean Med Sci 2018;33:e93.

25. Khokhar A, Naraparaju G, Friedman M, Perez-Colon S, Umpaichitra V, Chin VL. Comparison of A1C to oral glucose tolerance test for the diagnosis of prediabetes in overweight and obese youth. Clin Diabetes 2017;35:133-40.
26. Ehehalt S, Wiegand S, Körner A, Schweizer R, Liesenkötter KP, Partsch CJ, et al. Low association between fasting and OGTT stimulated glucose levels with $\mathrm{HbA1}$ c in overweight children and adolescents. Pediatr Diabetes 2017;18:734-41.

27. Yoon JS, So CH, Lee HS, Hwang JS. Glycated hemoglobin A1c as a screening test for detecting type 2 diabetes mellitus in obese children and adolescents. J Pediatr Endocrinol Metab 2018;31:503-6.

28. Selvin E, Francis LM, Ballantyne CM, Hoogeveen RC, Coresh J, Brancati FL, et al. Nontraditional markers of glycemia: associations with microvascular conditions. Diabetes Care 2011;34:960-7.

29. Chan CL, Pyle L, Newnes L, Nadeau KJ, Zeitler PS, Kelsey MM. Continuous glucose monitoring and its relationship to hemoglobin A1c and oral glucose tolerance testing in obese and prediabetic youth. J Clin Endocrinol Metab 2015;100:902-10.

30. Bergman M, Manco M, Sesti G, Dankner R, Pareek M, Jagannathan R, et al. Petition to replace current OGTT criteria for diagnosing prediabetes with the 1-hour postload plasma glucose $\geq 155 \mathrm{mg} / \mathrm{dl}(8.6 \mathrm{mmol} / \mathrm{L})$. Diabetes Res Clin Pract 2018;146:18-33.

31. Jagannathan R, Sevick MA, Fink D, Dankner R, Chetrit A, Roth J, et al. The 1-hour post-load glucose level is more effective than $\mathrm{HbAl}_{\mathrm{c}}$ for screening dysglycemia. Acta Diabetol 2016;53:543-50.

32. Abdul-Ghani MA, Abdul-Ghani T, Müller G, Bergmann A, Fischer S, Bornstein S, et al. Role of glycated hemoglobin in the prediction of future risk of T2DM. J Clin Endocrinol Metab 2011;96:2596-600.

33. Kasturi K, Onuzuruike AU, Kunnam S, Shomaker LB, Yanovski JA, Chung ST. Two- vs one-hour glucose tolerance testing: predicting prediabetes in adolescent girls with obesity. Pediatr Diabetes 2019;20:154-9. 